\title{
Practice format in training future preschool teachers
}

\author{
N.V. Belinova ${ }^{1 *}$ I.B. Bicheva ${ }^{2}$, and T.G. Khanova ${ }^{3}$ \\ ${ }^{1}$ K. Minin Nizhny Novgorod State Pedagogical University, Nizhny Novgorod, Russia \\ ${ }^{2}$ K. Minin Nizhny Novgorod State Pedagogical University, Nizhny Novgorod, Russia \\ ${ }^{3}$ K. Minin Nizhny Novgorod State Pedagogical University, Nizhny Novgorod, Russia
}

\begin{abstract}
The article deals with the issue of practice as the basic format of training preschool teachers at the university. Certain issues are brought to the spot such as contradictions between changing cultural, economic, and social environment and traditional, to large extent old-fashioned, regulations in university professional training, the readiness of employers to host and participate in the management of practice activities, the willingness of the teaching staff to mentoring collaboration, the expectation of trainees. The necessity to renovate the system of training is vividly highlighted by the results of the survey held among all the participants of practice. Through the reflexive model of pedagogical practice as an element of the curriculum for training a preschool teacher at a university, we analyze the changes to be introduced in target, technological, content, methodological, and efficiency components.
\end{abstract}

\section{A problem statement}

The modernization of the pedagogical education system puts forward updated requirements to a future specialist model, such as to have high-level professional training in the educational discourse of work with preschoolers, to follow, probe, analyze strategic trends and requirements of major federal educational acts together with regional regulations and work on curricula, develop and critically introduce own educational products under the requirements of federal and professional standards [1]. Practice-oriented activity is an integral component in training future specialists for professional activity, which in turn makes the topic of the research relevant today [2].

The value of teaching practice lies in creating the student's professional experience, which further contributes to the design and development of a natural reflexive environment [3]. Pedagogical practice, firstly, helps future specialists to determine the level of their readiness for professional activity as a teacher, as well as to analyze the formation of the necessary personal characteristics for solving professional problems in the future. Pedagogical practice allows to implement theoretical knowledge into practice and becomes an important structural element in understanding the motives of professional activity [4]. However, the generalized level of the research in pedagogical education to some extent

* Corresponding author: ipcs-profped@yandex.ru 
does not correspond to the requirements for the content, nature of the activity, and personal qualities of a future specialist in the process of preparing for his professional activity [5].

The analysis of the study of the actual state of things in the organization of students' pedagogical activity in the kindergarten emphasizes several contradictions that require detailed contemplation and hereinafter solving [6].

1. Firstly, it is a disagreement between the mass nature of the organization of pedagogical practice and the individual nature of cognition by the teacher's activities [7].

2. Secondly, is the general contraction in science when a gap is observed in fundamental theoretical research and practice. Sometimes when theory finds its way to the practice the knowledge needs to be updated. To remove the gap means to synchronize and instantly coordinate efforts and time both by those who develop the theory and practical performers, that probe. The conclusion should be formulated jointly. The contradiction on the whole states the absence of effective collaboration [8].

3. At last, the changing socio-economic environment put forward such personal-oriented phenomena as creativity, creative thinking, emotional intelligence, empathy, and others. And the problem is that the requirements for modern educators do coincide with the traditional training frame determined to be the pedagogical education at the university. Thus social expectations do not match the state of things [9].

The search for solutions to the contradictions, both in theoretical and practical terms, leads to the need to identify ways to improve the organization of practice-oriented activities in a pedagogical university.

Numerous studies of modern authors put forward certain requirements for the quality of preschool education, which is considered as a prerequisite for the successful development of every child [10]. A certain place in the problem picture is occupied by the idea that the quality of preschool education includes the effective activity of all preschool organizations, which implies educational services that meet the demands of end consumers - parents and the society on the whole. In this regard, we can say that the quality of preschool education is inextricably linked with the professional competencies of teachers of preschool organizations. The special role of the teacher, in this case, is to organize work with children and parents competently to achieve a common goal [11].

The restructuring of the education system puts forward new and higher requirements for the teacher's professional activities and qualifications. This trend is manifested not only in Russian education but also in the global education market. Improvement of the new professional education system has a global impact on the effectiveness of the implementation of all levels of education [12]. Accordingly, the training of a highly qualified teacher is the target task of the entire education system of the country [13].

Adopted legislative acts approved at the federal level, for example, the professional standard, reflect the idea that a modern graduate of a pedagogical university should be able to implement professional activities under prescribed labor functions, labor actions, and professional competencies.

Thus, we can outline some thesis on the modern state of things in practice-oriented training of preschool teachers.

Traditional is the demand that the professional training of a teacher should be carried out in two directions: theoretical and practical [14].

Practice-oriented activity is the basis for the formation of professional experience in the pedagogical sphere in all its diversity and complexity. The pedagogical staff of kindergartens notes that in many cases young specialists do not encounter difficulties and problems at the initial stages of professional activity, but in the future, the professional growth of a young specialist is often hampered due to his lack of flexible adaptation to the changing conditions of the educational organization's environment and freely solving instant tasks, that take place in routine of kindergarten [15]. As a result, a graduate starting 
a professional career feels the insufficiency of some instant instruments and mechanisms in solving everyday routine problems in work with children, collaboration with the professional community, or interaction with parents.

The fact that each type of activity has its content is obvious. The practice is no exception. The key points in traditional practice are organizational and substantive provision, the initial state of the trainees, the goal, practical activity, means, and conditions of activity, the result obtained [16].

Thus, the various views we have studied on the content of pedagogical practice allows us to conclude that the core of the pedagogical practice is aimed at consolidating professional competencies. Following Russian standards, teachers should have general cultural and professional competencies, that is, be competent [17].

Scrutinizing the content of pedagogical practice, it is advisable to turn to the concept of "pedagogical practice" itself. Referring to the works of modern researches we find the general opinion that pedagogical practice is the dominant element in the process of obtaining basic skills and abilities of future teachers.

There is a minor report, however, that puts forward personal characteristics of future preschool teachers also claimed as important for further self-development, selfdetermination [18]. The teacher should work at personality to be capable of developing personal traits in his pupils, provide support in their psycho-physiological development [19].

Summarizing what has been said, pedagogical practice is a key stage in the professional development of the future teacher, revealing the knowledge, skills, and competencies obtained in the theoretical field.

The reviewed scientific literature indicates that there is no consensus about teaching practice. Therefore, it is desirable to analyze the organization of practice-oriented activities, the educational organization of the student from the researchers' claims.

We propose together with other researchers to create a practice in an educational organization as an "integrated educational process for the formation of a future teacher's professional, communicative, organizational, competence" [20]. Also, the process itself is defined as the gradual implementation of the content of the practices.

Special attention is paid to the process of thinking about each stage of pedagogical practice, it is necessary to perform an analyze difficulties and problems at the end of the practice, at the conclusive seminars at the university, at comprehensive conferences or online supportive courses, services [21].

In turn, great importance is attached to research students during teaching practice. We share the opinion that the forwarding characteristic of a student as a subject is professional activity - initiative, independence in decision-making and creativity, positive communication, and attitude to external life, colleagues, students, oneself. Therefore, from a scientific point of view, the research activity of students during practice becomes the main condition for the formation of these qualities.

All and all in the system of pedagogical education practice has traditionally been considered a multifaceted and multifunctional phenomenon as part of the process of professionalization of the individual, aimed at developing professional skills and abilities, which are a means of consolidating theoretical knowledge and socialization in society.

Traditionally, in the system of Russian pedagogical education, the pedagogical practice was a mandatory form of teacher training for pre-graduation and graduation courses (4-5 courses of study). 


\subsection{The objective of the work}

In Minin Nizhny Novgorod State Pedagogical University practice is based on the study of general professional disciplines and disciplines of subject training, which constitute its theoretical foundation: "Theory of training and education", "General and family pedagogy", "Theory and methods of the upbringing of preschool children", "Psychology of development", "Psychology of children of preschool, primary school, and adolescent ages","Preschool pedagogy", etc.

The practice involves the practical development of various types of the pedagogical activity, mastering the basics of pedagogical culture, and the formation of readiness for pedagogical creativity.

The practice is carried out in preschool educational organizations according to the schedule of the educational process:

1. Pedagogical practice in preschool education - aimed at getting and mastering basic professional skills, embraces all education directions according to the curriculum.

2. Practice in early age groups - encounters professional activity with small children aged 1-3 years old.

3. Summer training practice - aimed at sport and physical activities organized at kindergartens.

4. Methodical practice - aimed at getting and mastering basic professional skills in preschool education management,

5. Undergraduate practice - is held at the final grade, aimed at researching preschool education.

To analyze the background of practical professional training there was held a survey embracing several categories of the participants: managers, students, educators at kindergarten, and supervisors from the university.

\section{Materials and the results of the research}

Analysis of the state of the problem in the modern educational context revealed some urgent issues.

The processing of the survey showed that the total number of respondents was 58 people, including $53.4 \%$ - student trainees, $22.4 \%$ - an educator of an educational organization, $12.1 \%$ a supervisor of practice from a university.

This survey consisted of 14 questions. To the question "Choose the most appropriate definition of practice? (several options) " there were answers: $86.2 \%$ - the practical component of the process of preparing for professional activity, $63.8 \%$ - part of the educational process in the training of future teachers, 39.7\% - the type of educational and research activities of students, $36.2 \%$ - getting into the field of professional activity, $6.9 \%$ an independent element of the educational process at the university, in no way connected with theoretical disciplines.

To the question "What can be considered the base of practice in the modern preschool educational context? (several options) " there were answers: $100 \%$ - municipal preschool educational organizations, $81 \%$ - private kindergartens, $70.0 \%$ - development centers, $39.7 \%$ - children's camps, 34.5\% - family kindergartens, $15,5 \%$ - entertainment and animation centers, $10.3 \%$ - children's rooms in shopping centers, $6.9 \%$ - own family and quantorium, $5.2 \%$ - other, $1.7 \%$ - a large family with many children.

To the question "How much is the need for practice in teacher training?" there were answers: $96.6 \%$ - practice is very important in teacher training.

To the question "Who should play the main role in organizing the practice of students (to determine the content of the practice, the distribution of responsibilities, to do control)?" 
there were answers: $77.6 \%$ - supervisor of practice from the university, $19 \%$ - head of the educational organization (or his deputy).

To the question "What requirements should a modern practice base meet? (several options) " there were answers: $89.7 \%$ - modern material and technical equipment, $82.8 \%$ the willingness of the pedagogical team to work with students (high level of loyalty), $81 \%$ highly professional staff, $50 \%$ - special training of teachers for support trainees, etc.

Further, the survey included questions for a different contingent of respondents, namely: for a student-trainee, for the head of the educational organization, for the teacher of the educational organization.

For a student-trainee, the question followed like this: "I will choose the base of practice", to which there were answers: $33.3 \%$ - the one recommended by the supervisor of the practice from the university, $20 \%$ - the place of my future work (where I will go to work), 20\% - myself according to the principle "close to home", $15.6 \%$ - ideally when the university sends to kindergarten - you don't have to make a decision yourself

To the question for the head of the educational organization "How do you interpret the very phenomenon of practice. Its organization in your kindergarten/center, other? " there were answers: $85.7 \%$ - this is a very important and useful thing, $57.1 \%$ - the opportunity to select future workers, $39.3 \%$ - great help to the kindergarten in daily routine, $28.6 \%$ - the opportunity to learn something new from the student, $28.6 \%$ - the opportunity to organize and implement labor-intensive projects, $14.3 \%$ - the opportunity to unload their teachers, $10.7 \%$ - the opportunity to strengthen the position of the kindergarten in the eyes of the authorities and the professional community, $7.1 \%$ - a burden for teachers and management, $7.1 \%$ practice has outlived itself as an educational component, it does not give real experience, $3.6 \%$ - this is probably a good thing, but I will never accept trainees, $3.6 \%$ is a waste of teachers and students' time.

To the student's question "What will I do in practice?" there were answers: $31.1 \%$ - as a rule, I have a clear task of what to do and at what time, $24.4 \%$ - I want to communicate with children, do something together, $20 \%$ - I can visualize just in general terms, but I will get a clear picture in the base of practice, $13.3 \%$ - I will organize active events.

To the question "What activities are necessary to be held in the practice? (several options) " there were answers: $77.6 \%$ - an introductory meeting with students, teachers, and the supervisor of the practice from the university, $62.1 \%$ - interim meetings to discuss the course of practice, current issues and problems, 58.6\% - direct communication of teachers with the supervisor of practice from a university, $55.2 \%$ - a final meeting with all participants in the practice, $48.3 \%$ - collecting feedback about students from teachers, $39.7 \%$ - compulsory reflection at the end of each day of practice with the participation of students and teachers, $31 \%$ - a collection of reviews about students from children, $12.1 \%$ the permanent presence of the supervisor of practice from the university in the base of practice, monitoring of student activities

To the question "What elements of professional activity are most important for a trainee?" there were answers: $86.2 \%$ - organization of daily regime moments (reception of children, morning exercises, organization of meals, walks, sleep), $82.8 \%$ - organization of an educational organization, $75.9 \%$ - communication with experienced teachers in the process of performing labor actions, $56.9 \%$ - interaction with parents of children, $55.2 \%$ registration of activities, production of didactic aids, $50 \%$ - participation in innovative/experimental activities, 41.4\% - interaction with other students during labor activities, 32, $8 \%$ - work on the improvement of the group/site of the kindergarten

To the question "What practice is the most effective?" there were answers: $43.1 \%$ compact, in one period of time, $39.7 \%$ - distributed, for several days a week in practice the rest of the days theoretical training, $10.3 \%$ - I find it difficult to answer. 
To the question "How justified are the tasks for the development and implementation of projects in practice" there were answers: $29.3 \%$ is great, interesting, interactive, $29.3 \%$ is possible only in senior courses, $24.1 \%$ of the project - it is the main didactic unit in modern education.

Thus, there are many contradictions in the organization of practice and the readiness of the teaching community to assist the university in its implementation.

Based on the analysis and comprehension of the theoretical and methodological studies and the data obtained during the survey of the professional community, we attempted to design a model of pedagogical practice in the structure of the main professional educational program for training a preschool teacher at a university at the bachelor's level.

Under the federal state educational standard of higher education in psychological and pedagogical education, the following types of practices are defined: educational and industrial. The types of educational practices are introductory, technological (design and technological), and research work. The types of industrial practice are pedagogical, technological (design and technological), and research work. The fundamental difference between educational and industrial practices is that at the level of educational practice, introduction to professional activities and the obtaining of primary skills occur, while industrial practice involves the development of competencies of future teachers already in the process of performing labor actions and implementing labor functions under the professional standard. The standard also assumes the possibility of determining additional types and types of practices by the educational organization on its own accord, which provides professional training for future teachers.

The proposed model includes 5 components: target, technological, content, methodological, and efficiency.

The basic goals of organizing the practice are integration into professional activities, the development of professional competencies through the consistent and systematic organization of professional activities - the performance of labor actions and the implementation of labor functions, as well as the development and improvement of the social and personal qualities of the teacher, such as the ability to communicate with participants in the educational process (children, colleagues, parents (legal representatives) of pupils, social partners), skills of self-organization and self-development, tolerance and empathy, and much more.

The most important components in the organization of practice are the technological and content components.

The technological component determines the logistics of organizing the educational process during practice. The first aspect is to define the base of practice. The choice of a practice base is a variable process since this can be:

- a supporting platform of the university, where the head of practice directs students;

- an educational organization that sent a student to targeted training. It seems justified that the student will carry out professional activities in kindergarten, where he will subsequently be employed;

- educational organizations that have sent a request to send students to practice to perform some jobs comparable to the professional activities of a future graduate.

Analysis of the current situation shows that not every educational organization is ready and can become a practice base.

The study of best practices also confirms the conclusions about the requirements for the practice base:

- availability of a modern resource base;

- interaction with the university in the framework of solving professional, research problems; 
- the willingness of the teaching staff to carry out additional tasks of providing mentoring assistance, accompanying practice in kindergarten;

- the presence of a protocol for organizing practice, which defines not only the sequence of actions and the procedure for admitting students to practice but also provides for regular events and educational events that contribute to the integration of students into the pedagogical process of the kindergarten.

Modern and justified is the idea of locating a base department in a kindergarten, or the creation of a "university kindergarten" by analogy with the "university school" project, which largely optimizes all processes in organizing students' practice, reduces the number of approvals and makes, in general, the rules of interaction between the university and the kindergarten more transparent and efficient.

The organization of the educational process during practice is determined by the practice program, which is a mandatory component of the main professional educational program. The program defines the competencies formed in the course of practice, knowledge, and skills. The type of practice, format, and timing of the course is indicated, a set of activities, stages, credit points, material and technical requirements, etc.

The most controversial aspect is now the organization of supervision and control of the practice. Now the supervisor of the practice from the university does not have the opportunity to stay with the students in the base of practice all the time. The main function of control rests with the management of the kindergarten. The decisive factor, in this case, is the experience of carrying out practices, the development of a certain regulation for admitting and accompanying students, the appointment of those responsible in the kindergarten for organizing assistance. Regulations of this kind seem to be problematic since each kindergarten has its scheme of practice; in the absence of a centralized approach, contradictions of various kinds are frequent. Therefore, as a recommendation, we propose the development of regulations for organizing practice in the base of a kindergarten.

The content component is implemented on the principles of consistency, complexity, integrativity, variability, and continuity.

The variability lies in the type and format of practice. The most flexible element is the practice format, as it is determined by the resource potential of the kindergarten, regional specifics, current tasks, and socio-cultural situation.

The methodological component includes active and interactive methods. The most relevant now is information and communication methods that correspond to modern trends in the digitalization of education and society as a whole. Within the framework of clinical practice, the project method is the leading method; reflective and creative methods should dominate in graduation courses.

The result of the practice is the formation of professional competencies of bachelors, future teachers of preschool education, necessary for the implementation of labor functions under the requirements of the professional standard.

As a result, the entrance to the profession is carried out, the readiness to solve professional problems is ensured following the modern situation, social specifics.

\section{Conclusions}

In the course of the survey, a high degree of interest in the professional community in practice as the main way of training preschool teachers was revealed. The survey revealed that many people define the practice as an important component of the educational process.

The main base of practice, most respondents point to traditional organizations with clearly defined functionality and work regulations - preschool educational institutions, development centers, private kindergartens. Innovative forms are less popular because they cannot provide comprehensive universal training of a teacher. However, they are also of 
certain interest for the organization of practice, since they can be considered as tools for the individualization of educational activities - for the development of certain skills.

While the management of educational organizations is ready to assist in organizing practice, teachers regard this additional activity as an unnecessary burden, the motivational readiness of teachers is thus defined as below average-low.

The main role in organizing the internship is still assigned to the supervisor of the practice from the university. It is necessary to ensure a clear interaction between the university and the base of practice when organizing practice, to develop universal regulations for conducting practice based on an educational organization.

An interesting point is that many note the need for special training of teachers to accompany students in kindergarten.

The model proposed is based on the results of research work is reflective, since we have attempted to comprehend and systematize the experience of conducting the practice in kindergarten.

\section{References}

1. N.V. Belinova, I.B. Bicheva, L.V. Krasilnikova, T.G. Khanova, A.V. Hizhnaya, Lecture Notes in Networks and Systems, 91, 422-429 (2020)

2. M.R. Burchinal; D. Cryer, R.M. Clifford, et al. Applied Developmental Science 6, 1, 2-11 (2002)

3. I.Y. Burkhanova, O.I. Vaganova, M.M. Kutepov, Z.V. Smirnova, E.A. Chelnokova, Lecture Notes in Networks and Systems, 73, 1057-1063 (2020)

4. I.Y. Burkhanova, G.L. Drandrov, S.S. Ivanova, A.V . Stafeeva, N.B. Vorobyov, V.A. Balchugov, E.V. Ignatyeva, International Journal of Applied Exercise Physiology, 9, 4, 117-124 (2020)

5. Karen E. Diamond, Douglas R. Powell, Journal of Early Intervention, 3, 1, 75-93 (2011)

6. L. Evans, Oxford Review of Education, 28,1, :123-137 (2002)

7. N.V. Ivanova, T.M. Sorokina, Revista Inclusions, 7, 100-118 Special issue (2020)

8. A.S. Kurbatova, I.B. Bicheva, N.V. Ivanova, S.A. Zaitseva, L.V. Krasilnikova, Revista Inclusions, 7. 158-173 (2020)

9. T.Y. Medvedeva, O.A. Sizova, N.V. Syrova, L.P. Depsames, S.I. Yakovleva, R.A. Ulyanova, AD ALTA-Journal of Interdisciplinary Research, 10(1), 31-34 (2020)

10. I.Y. Burkhanova, G.L. Drandrov, N.B. Vorobyov, A.V. Stafeeva, S.S. Ivanova, N.V. Bystrova, International Journal of Applied Exercise Physiology, 9 (8), 18-25, (2020)

11. H. Caton, D. Greenhill, Proceedings of the 7th European Conference on Games-Based Learning Reading. P. Escudeiro, C. Vas de Carvalho (eds.). Academic Conferences International Limited, 88-96 (2013)

12. Dominguez, J. Saenz-de-Navarrete, L. de-Marcos. Computers \& Education, 63, 380$392(2013)$

13. Carl J. Dunst, Infants \& Young Children, 28,3 210-219 (2015)

14. E. Ilaltdinova, I. Lebedeva, R. Arifulina, S. Frolova, T. Belyaeva, M. Lebedeva, International Journal of Applied Exercise Physiology, 9, 6, 118-124 (2020)

15. O.A. Kozyreva, Vestnik of Minin University, 8 (2), 1-19. https://doi.org/10.26795/2307-1281-2020-8-2-1 (2020) 
16. A.S. Kurbatova, N.V. Rubtsova, A.Y. Vershinina, T.K. Belyaeva, A.G. Pukhova, Turismo-Estudos ed Praticas (2020).

17. O.I. Vaganova, A.V. Lapshova, M.M. Kutepov, S.N. Tatarnitseva, E.V. Vezetiu, Amazonia Investiga, 9, 369-375 (2020)

18. T.A. Serebryakova, I.A. Koneva, E.M. Kochneva, I.S. Begantsova, O.V. Ladykova, T.T. Shchelina, O.V. Suvorova, Turismo-Estudos ed Praticas, 2316-1493 (2020)

19. A.M. Safina, R.U. Arifullina, A.M. Ganieva, O.A. Katushenko, Tarih Kultur ve Sanat Arastirmalari Dergisi-Journal of History Culture and Art Research, 9 (2), 61-71 (2020)

20. E.V. Yashkova, N.L. Sineva, S.V. Semenov, O.I. Kuryleva, A.O. Egorova, Lecture Notes in Networks and Systems, 91, 149-155 (2020)

21. J. Banfield, B. Wilkerson, Contemporary Issues in Education Research, 7, 4, 291-298 (2014) 